\title{
Joining of Steel to Aluminum Alloy by AC Pulse MIG Welding
}

\author{
Hyoung Jin Park ${ }^{1}$, Sehun Rhee ${ }^{1}$, Mun Jin Kang ${ }^{2}$ and Dong Cheol Kim ${ }^{2}$ \\ ${ }^{1}$ Department of Mechanical Engineering, Hanyang University, Seoul 133-791, Korea \\ ${ }^{2}$ Advanced Welding \& Joining R\&D Division, Korea Institute of Industrial Technology, Incheon 406-840, Korea
}

\begin{abstract}
This study evaluates the characteristics of welds resulting from joining dissimilar alloys, steel SPRC440 and aluminum alloy $6 \mathrm{~K} 21$. The joint was obtained by means of AC pulse MIG welding, which alternates between direct current electrode positive (DCEP) and direct current electrode negative (DCEN), based on the EN ratio.

In order to evaluate the AC pulse MIG welding for the dissimilar joining of steel SPRC440 to Aluminum alloy $6 \mathrm{~K} 21$, the arc characteristics in relation with varying EN ratios were analyzed. The AC pulse MIG welding process showed good gap bridging ability. The joining quality of the dissimilar alloys was evaluated by the analyzing the intermetallic compound layer. [doi:10.2320/matertrans.M2009105]
\end{abstract}

(Received March 26, 2009; Accepted June 18, 2009; Published August 25, 2009)

Keywords: dissimilar welding, AC pulse metal inert gas (MIG) welding, EN ratio, gap bridging, intermetallic compound layer

\section{Introduction}

Recently as interest in pollution and environmental issues has increased throughout the world, the automotive industry has been actively conducting research on the improvement of fuel efficiencies by reducing vehicle weight. ${ }^{1-3)}$ One of the main methods of reducing vehicle weight is to use a light aluminum alloy with excellent corrosion resistance for fabricating the car body. This aluminum alloy substitutes for the steel structures employed previously. ${ }^{4-8)}$

The general characteristics of an aluminum alloy are its high electrical and thermal conductivity and its low melting point. Therefore, burn-through occurs frequently when the aluminum sheet is welded by using the metal inert gas (MIG) welding process, while spatter occurs at low-range welding currents. Even though pulse MIG welding causes almost no spatter or burn-through, burn-through may occur when there is a gap in a butt or lap joint. The difficulty of aluminum arc welding makes good-quality welding difficult to achieve; this has resulted in active research into obtaining good welding quality from aluminum alloy welding.

Steel and aluminum alloy are the most widely used metals in various industries. When joining steel to an aluminum alloy, it is not easy to obtain good welding quality because their physical characteristics greatly differ. In particular, the intermetallic compound layer that appears between the dissimilar welding parts makes them brittle, thereby resulting in significantly low strength and deformation. In order to minimize the brittleness of the intermetallic compound layer, its thickness must be $10 \mu \mathrm{m}$ or less. ${ }^{9,10)}$ Hence, in order to use aluminum alloy sheets to fabricate a car body, the drawbacks of aluminum arc welding must be remedied, along with those of methods used previously in the automotive industry for joining of dissimilar alloys such as steel sheet and aluminum alloy sheets.

In this study, steel was weld brazed to aluminum alloy using AC pulsed MIG welding, which alternates between DC electrode-positive and DC electrode-negative based on the electrode-negative (EN) ratio. The resulting weld characteristics were evaluated.

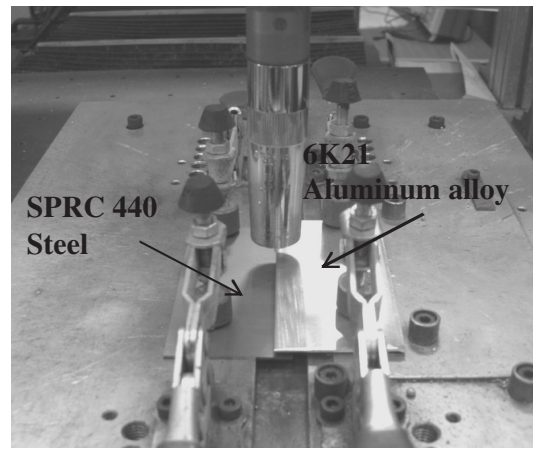

Fig. 1 Experimental setup for AC pulse MIG welding.

\section{Experimental Setup and Procedure}

The experimental set-up is shown in Fig. 1. $1.4 \mathrm{~mm}$-thick SPRC440 steel plates and $1.6 \mathrm{~mm}$-thick $6 \mathrm{~K} 21$ aluminum alloy plates were welded at the bottom part and top part respectively by using a lap joint. 4043 aluminum alloy wire having a diameter of $1.2 \mathrm{~mm}$ was used for as the filler wire, and the weld were shielded by using argon gas flowing at $20 \ell / \mathrm{min}$ for welding. The surfaces of the base metals were cleaned with acetone before welding. Tables 1,2 , and 3 shows, respectively, the chemical composition of the three components: 6K21 aluminum alloy, SPRC440 steel, and 4043 aluminum alloy wire.

The AC pulse MIG welding used in this study generates two sections, DCEP and DCEN, and cyclically alternates between these sections. Figure 2 shows the current waveform for AC pulse MIG welding. ${ }^{11)}$

The current waves of AC pulse MIG welding is expressed as the EN ratio, and the EN ratio is defined as follows (eq. (1)).

$$
\mathrm{EN}=\left[\frac{\left(\mathrm{I}_{\mathrm{EN}} \times \mathrm{T}_{\mathrm{EN}}\right)}{\left(\mathrm{I}_{\mathrm{EP}} \times \mathrm{T}_{\mathrm{EP}}\right)+\left(\mathrm{I}_{\mathrm{EN}} \times \mathrm{T}_{\mathrm{EN}}\right)} \times 100 \%\right]
$$

In the eq. (1),

$\mathrm{I}_{\mathrm{EN}}$ : The average current of the section EN, (A)

$\mathrm{I}_{\mathrm{EP}}$ : The average current of the section EP, (A)

$\mathrm{T}_{\mathrm{EN}}$ : The time of the section EN, (s)

$\mathrm{T}_{\mathrm{EP}}$ : The time of the section EP, (s) 
Table 1 Chemical composition of 6K21 aluminum alloy (mass\%).

\begin{tabular}{cccccccccc}
\hline $\mathrm{Si}$ & $\mathrm{Fe}$ & $\mathrm{Cu}$ & $\mathrm{Mn}$ & $\mathrm{Mg}$ & $\mathrm{Cr}$ & $\mathrm{Zn}$ & $\mathrm{Ti}$ & Others & $\mathrm{Al}$ \\
\hline 1.00 & 0.13 & 0.01 & 0.07 & 0.54 & 0.01 & 0.01 & 0.01 & 0.02 & $\mathrm{RE}$ \\
\hline
\end{tabular}

Table 2 Chemical composition of SPRC440 steel (mass\%).

\begin{tabular}{cccccc}
\hline $\mathrm{C}$ & $\mathrm{Si}$ & $\mathrm{Mn}$ & $\mathrm{P}$ & $\mathrm{S}$ & $\mathrm{Fe}$ \\
\hline 0.08 & 0.01 & 1.43 & 0.018 & 0.002 & $\mathrm{RE}$ \\
\hline
\end{tabular}

Table 3 Chemical composition of 4043 aluminum alloy wire (mass\%).

\begin{tabular}{cccccc}
\hline $\mathrm{Al}$ & $\mathrm{Si}$ & $\mathrm{Fe}$ & $\mathrm{Mn}$ & $\mathrm{Zn}$ & $\mathrm{Cu}$ \\
\hline 95.3 & 4.2 & 0.4 & 0.02 & 0.03 & 0.05 \\
\hline
\end{tabular}

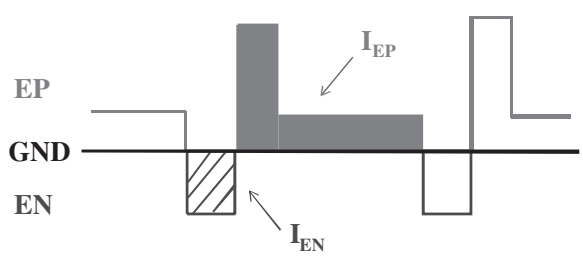

Fig. 2 Typical current waves of an AC pulse MIG welding.

\section{Results and Discussion}

\subsection{The arc characteristics of AC pulse MIG welding}

Figures 3 and 4 indicate the results of the wire melting phenomena in relation to the EN ratio from the joining of the dissimilar metal alloys, SPRC440 steel and 6K21 aluminum alloy. For the experiment, the arc-melting phenomenon of the wire was observed at 5000 frames per second by using a highspeed camera. The average welding current was set at $47 \mathrm{~A}$. The welding voltage was $16.7 \mathrm{~V}$, and welding speed was $0.5 \mathrm{~m} / \mathrm{min}$.

Figure 3 shows the high-speed camera images during a one-drop pulse and the welding voltage and welding current waveform of DC pulse MIG welding. It is observed that arc roots are concentrated on the surface of the base metal. Such a concentration provides the heat input to the base metal, thereby causing burn-through to occur in the case of the aluminum sheet welding.

Figure 4 shows the high-speed camera images during a one-drop pulse and the welding voltage and welding current waveform when the EN ratio of AC pulse MIG welding is set at $20 \%$.

In the base current section (h)-(l) of the EN polarity, it is observed that arc roots uniformly cover the end of melting filler wire rather than base metal. Therefore, the wires are

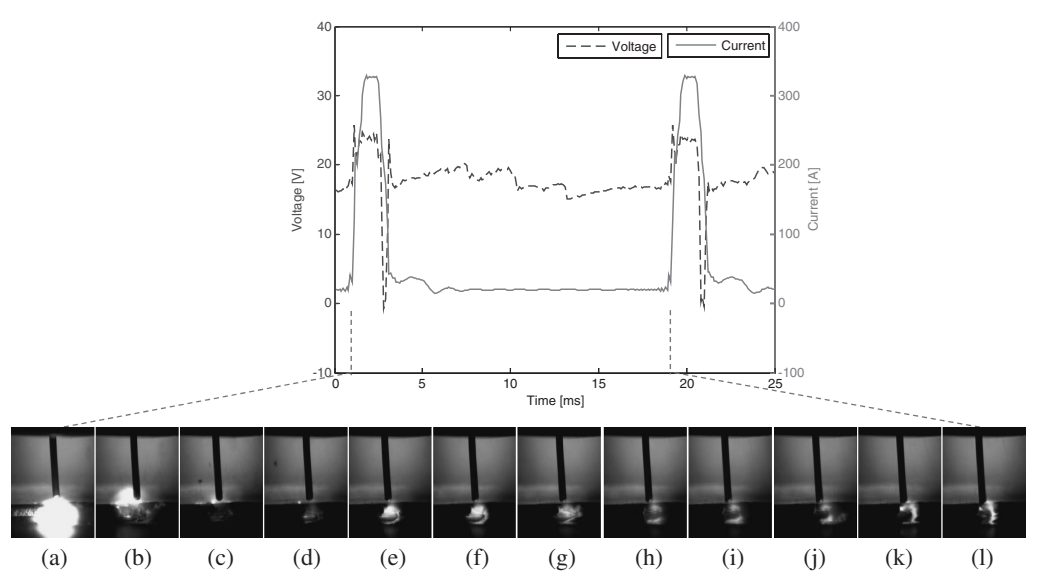

Fig. 3 The welding current and voltage waveforms of the DC pulse MIG.

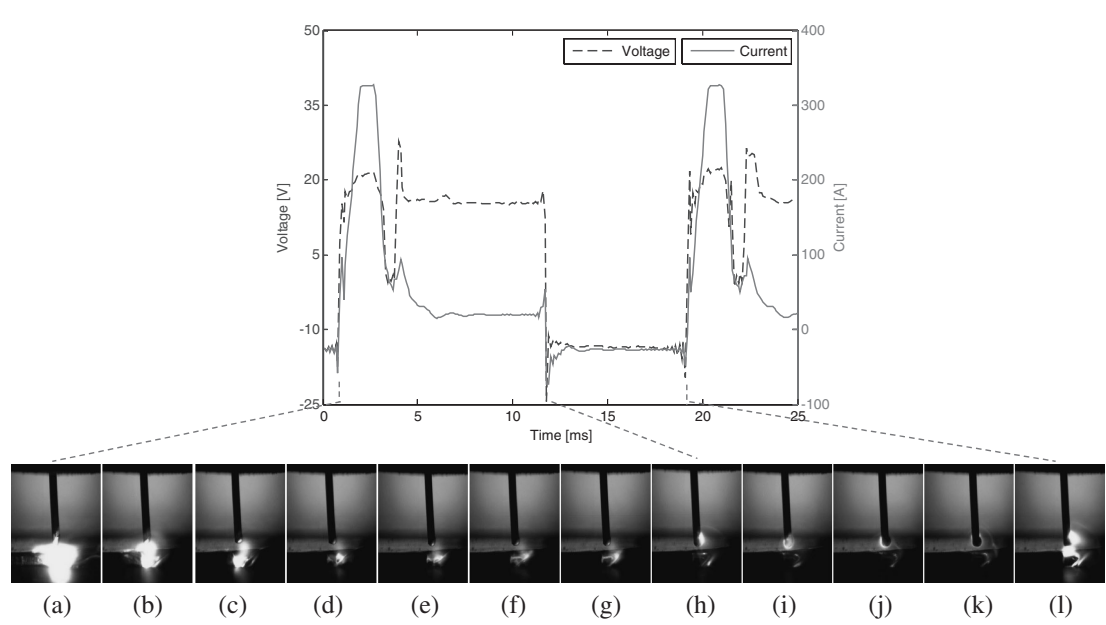

Fig. 4 The welding current and voltage waveforms of the AC pulse MIG at EN ratio of $20 \%$. 
Table 4 Gap bridging with the EN ratio.

\begin{tabular}{|c|c|c|c|}
\hline Gap & \multirow{2}{*}{$0 \mathrm{~mm}$} & \multirow{2}{*}{$0.5 \mathrm{~mm}$} & \multirow{2}{*}{$1.0 \mathrm{~mm}$} \\
\hline EN ratio & & & \\
\hline \multicolumn{4}{|l|}{$0 \%$} \\
\hline \multicolumn{4}{|l|}{$10 \%$} \\
\hline $20 \%$ & & & \\
\hline
\end{tabular}

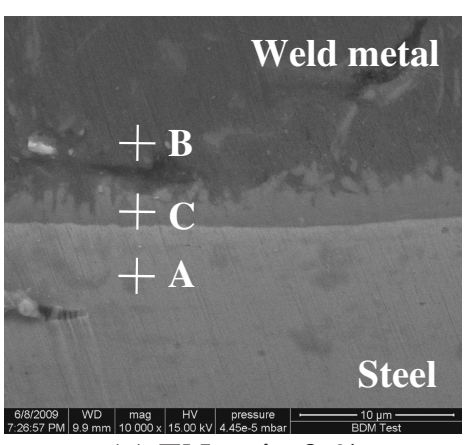

(a) EN ratio $0 \%$

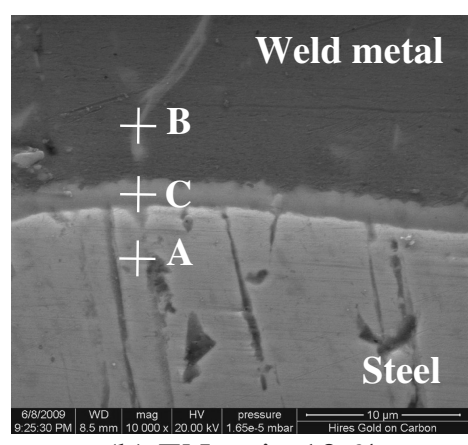

(b) EN ratio $10 \%$

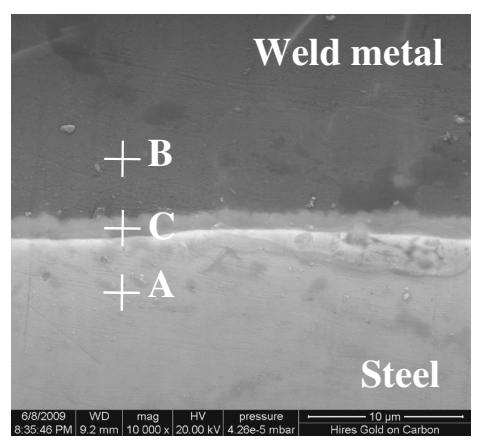

(C) EN ratio $20 \%$

Fig. 5 SEM analysis of SPRC440 joining of SPRC 440 steel to aluminum alloy $6 \mathrm{~K} 21$.

directly heated. The wire melting speed increases, compared to the case where $\mathrm{EN}$ ratio $0 \%$, which reduces the heat input applied to the base metal. In contrast to DC pulse MIG welding, less heat input is applied and burn-through phenomena arising from aluminum sheet welding can be avoided. In addition, as the EN ratio increases, the wire melting speed increases, resulting in higher deposition rates.

\subsection{Gap bridging ability by AC pulse MIG welding}

Table 4 indicates the bead formation corresponding to changes in the EN ratio and the gap for the joining of SPRC 440 steel and 6K21 aluminum alloy. All experiments were conducted under the same welding conditions at welding voltage of $16.7 \mathrm{~V}$, average welding current of $47 \mathrm{~A}$ and welding speed of $0.5 \mathrm{~m} / \mathrm{min}$.

As showed in Table 4, joining does not occur at the $1.0 \mathrm{~mm}$ gap with EN ratio of $0 \%$, and in line with increases in the EN ratio, the wire melting rate increases. This increases the deposition rates, thereby filling the $1.0 \mathrm{~mm}$ gap. Through the EN ratio and the gap change experiment, it is observed that as the EN ratio increases, the gap bridging ability improves significantly for the lap joint.

\subsection{The microstructure of the weld interface}

Because of the differing physical characteristics of steel and aluminum, their joining through melting produces an easily breakable, brittle intermetallic compound layer. The layer results in the weld having significantly low strength. However, when the thickness of the layer is $10 \mu \mathrm{m}$ or less, its drawbacks can be offset by the ductility of the base metal.

It is therefore suggested that in order to obtain good welding quality when a joining SPRC 440 steel to $6 \mathrm{~K} 21$ aluminum alloy, a thin intermetallic compound layer with a thickness of $10 \mu \mathrm{m}$ or less must be generated.

SEM analysis has been conducted in this study to evaluate the weldability in the AC pulse MIG welding for the dissimilar joining of SPRC440 steel to Aluminum alloy 6K21 under the following experimental conditions: $16.7 \mathrm{~V}$ welding voltage, $47 \mathrm{~A}$ average welding current, $0.5 \mathrm{~m} / \mathrm{min}$ welding speed, 0, 10, 20\% EN ratio, and $0 \mathrm{~mm}$ joint gap.

Figure 5 shows the results of the SEM analysis at EN ratio of 0,10 and $20 \%$. The $3.2 \mu \mathrm{m}, 1.34 \mu \mathrm{m}$ and $1.14 \mu \mathrm{m}$-thick intermetallic compound layers were observed at the EN ratio of 0,10 and $20 \%$, respectively. In other words, as the EN ratio increased, heat input to the base metal decreased. As a result, thin intermetallic compound layers were produced with good weldability.

Table 5 shows the results of the EDS analysis on base metal, weld metal, and interrmetallic compound layer. 
Table 5 EDS analysis of the weld interface (mass\%).

\begin{tabular}{cccccc}
\hline Position & EN ratio & $\mathrm{Al}(\%)$ & $\mathrm{Si}(\%)$ & $\mathrm{Mn}(\%)$ & $\mathrm{Fe}(\%)$ \\
\hline \multirow{3}{*}{ Steel } & $0 \%$ & 0.78 & 0.84 & 1.69 & 96.69 \\
\cline { 2 - 6 } & $10 \%$ & 0.44 & 0.34 & 1.96 & 97.26 \\
\cline { 2 - 6 } & $20 \%$ & 0.81 & 0.74 & 1.80 & 96.65 \\
\hline \multirow{3}{*}{ Welded metal } & $0 \%$ & 96.15 & 2.41 & 0.13 & 1.31 \\
\cline { 2 - 6 } & $10 \%$ & 97.41 & 1.37 & 0.10 & 1.12 \\
\hline \multirow{3}{*}{$\begin{array}{c}\text { Intermetallic } \\
\text { compound layer }\end{array}$} & $0 \%$ & 95.56 & 2.47 & 0.36 & 1.61 \\
\cline { 2 - 6 } & $10 \%$ & 62.42 & 7.12 & 0.60 & 29.86 \\
\hline
\end{tabular}
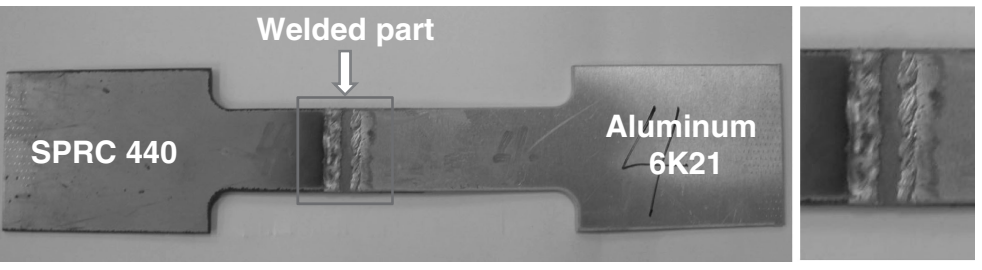

Fig. 7 The fracture location of the joint.

The base metal of SPRC440 steel mostly consists of Fe while the weld metal is comprised of Al. Analysis suggests that the intermetallic compound layer was mainly composed of extremely brittle compounds of $\mathrm{FeAl}_{3}$ and $\mathrm{Fe}_{2} \mathrm{Al}_{5}{ }^{12)}$ In addition, no component change was observed in welding metal and intermetallic compounds despite the change in EN ratio.

\subsection{The tensile strength test}

Figure 6 shows the results of the tensile strength values with the change in EN ratio of 0,10,20\% and gap of 0, 0.5, $1.0 \mathrm{~mm}$. As the EN ratio increased, the tensile strength increased regardless of the existence of a gap. With an increase in the EN ratio, the wire melting rate increased, and the gap was narrowed. As the intermetallic compound layer became thinner due to low heat input in the base metal, the tensile strength increased.

When joining heat-treated aluminum alloys (Type 6000), the tensile strength in the heat-affected zone decreases due to precipitation processes. Therefore, the heat-affected zone is the weakest zone with a loss of strength of about $30 \sim 40 \% .^{13)}$ The tensile test results show that the welding strength is about $173 \mathrm{MPa}$ at gap $0 \mathrm{~mm}$ and $\mathrm{EN}$ ratio $10 \%$, equal almost to $70 \%$ of that of the $6 \mathrm{~K} 21$ aluminum alloy. The fracture occurred in the heat-affected zone of the aluminum as show in Fig. 7.

\section{Conclusions}

This study drew the following conclusions from experiments on the joining of SPRC 440 steel and 6K21 aluminum alloy by AC pulse MIG welding:

(1) Based on the analysis of arc melting phenomena in relation to changes in the EN ratio, it was observed that as the

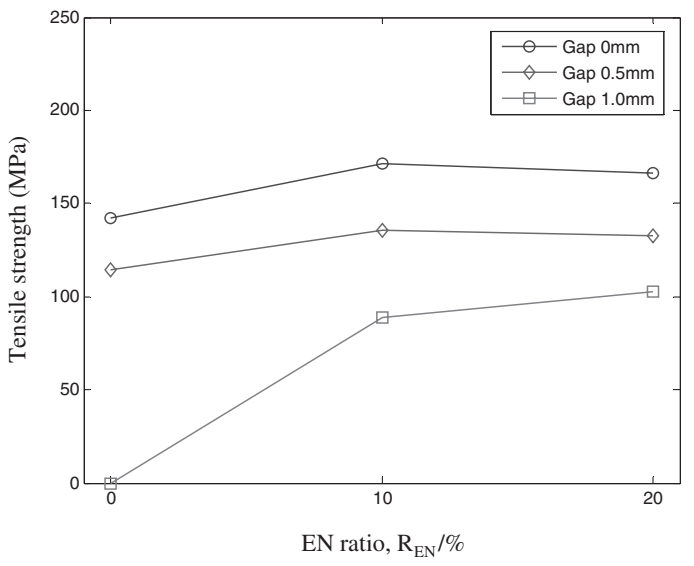

Fig. 6 Tensile strength of welded joints of SPRC 440 steel to aluminum alloy $6 \mathrm{~K} 21$
EN ratio increased, the deposition rate increased, and the heat input applied to the base metal decreased.

(2) Based on the analysis of the gap bridging experiment in relation to changes in the EN ratio, it was observed that as the EN ratio increased, the gap bridging ability improved significantly.

(3) Based on the SEM and EDS analyses, a thin intermetallic compound layer was obtained due to lower heat input to the base metal as the EN ratio increased.

(4) Based on the analysis of the tensile strength test in relation to changes in the EN ratio, it was observed that as the EN ratio increased, the tensile strength value improved with good gap bridging ability.

\section{REFERENCES}

1) P. Praveen and P. K. D. V. Yarlagadda: J. Mater. Proc. Technol. 164165 (2005) 1106-1112.

2) T. Watanabe, H. Takayama and A. Yanagisawa: J. Mater. Proc. Technol. 178 (2006) 342-349.

3) T. Aizawa, M. Kashani and K. Okagawa: Weld. J. 86 (2007) 119-124.

4) L. Laiping, C. Shanben and L. Tao: Mater. Sci. Eng. 394 (2005) 320-326.

5) T. Y. Kuo and H. C. Lin: Mater. Sci. Eng. 416 (2006) 281-289.

6) T. S. Kumar, V. Balasubramanian and M. Y. Sanavullah: Mater. Design 28 (2007) 2080-2092.

7) J. H. Dudas and F. R. Collins: Weld. J. 45 (1966) 241-249.

8) Y. M. Zhang and S. B. Zhang: Weld. J. 79 (1999) 202-206.

9) H. T. Zhang, J. C. Feng, P. He, B. B. Zhang, J. M. Chen and L. Wang: Mater. Sci. Eng. 499 (2009) 111-113.

10) K. J. Lee, S. Kumai, T. Arai and T. Aizawa: Mater. Sci. Eng. 471 (2007) 95-101.

11) T. Ueyama, H. Tong, I. Yazawa, M. Hirami, T. Kihara, K. Nakata and M. Ushio: Weld. Int. 18 (2004) 345-350.

12) M. J. Rathod and M. Kutsuna: Weld. J. 83 (2004) 16-26.

13) H. Schoer: Weld. Allied Proc. DVS-Verlag, (1998). 